Western University Scholarship@Western

1974

\title{
Identical Bids and Cartel Behavior
}

William S. Comanor

Mark A. Schankerman

Follow this and additional works at: https://ir.lib.uwo.ca/economicsresrpt

Part of the Economics Commons

Citation of this paper:

Comanor, William S., Mark A. Schankerman. "Identical Bids and Cartel Behavior." Department of Economics Research Reports, 7410. London, ON: Department of Economics, University of Western Ontario (1974). 
Research Report No. 7410

IDENTICAL BIDS AND CARTEL BEHAVIOR

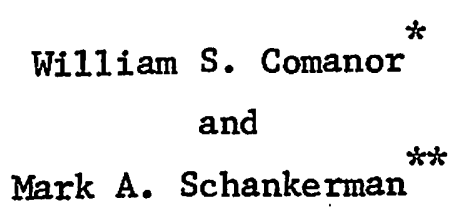

November, 1974

* Professor of Economics, University of Western Ontario.

${ }^{* *}$ Graduate Student of Economics, Harvard University. 


\title{
IDENTICAL BIDS AND CARTEL BEHAVIOR
}

\author{
William S. Comanor and Mark A. Schankerman
}

In this paper, we examine the reasonableness of inferring the existence of a cartel from patterns of identical bids among competing firms. In most discussions of antitrust policy, there has been general acceptance of the view that identical bids suggest the presence of an agreement. By what other route, it has been asked, could bids equal to the last cent be set except through an explicit arrangement? Posing the question in this manner, however, does not provide an answer.

Despite the widespread acceptance of this view, there is little analysis of the role that identical bids would play in a cartel agreement. The strategy of the paper is to assume the existence of a cartel and inquire into the likely pattern of bidding behavior which would result. We begin with a general discussion of cartel theory in open bidding markets. A model of cartel behavior in such markets is thus constructed from which some conclusions for antitrust enforcement are drawn.

This problem is important because of the past pattern of public policies. Since 1936, there has been a presumption that identical bids suggest, even if they do not demonstrate, the presence of collusive behavior. From that year to the present, federal agencies have been requested to report all

We are grateful to William F. Baxter for a number of helpful comments and suggestions. 
"collusive or identical bids" to the Attorney General."

The pattern of judicial judgment has been similar. Its clearest expression is in U.S. V. Pfizer, where the court stated:

Certainly, uniformity of price may be and has been considered some evidence tending to establish an illegal agreement. 2

While identical bids are not considered prima facie evidence of price fixing, it is widely accepted that they suggest such an arrangement. It is this presumption with which we are concerned.

Cartel objectives and Strategies

The classic purpose of a cartel is to realize price levels and profit margins by agreement among competing firms which could not be achieved in its absence. However, a necessary subsidiary objective is the maintenance of cartel stability and the discouragement of cheating by member firms. There is a strong incentive for firms party to a cartel arrangement to undercut an established price, if by so doing, they can increase their market share. However, if all firms behave in this fashion, the arrangement will founder on the rocks of individual self-interest to the mutual detriment of all. The question remains, then, as to what actions are likely to be taken in establishing a cartel arrangement to discourage cheating by member firms.

1 Joint Economic Committee, U.S. Congress, Bids Involving Identical Bids Reported to the Department of Justice by the Federal Procurement Agencies in the Years 1955-1960, Washington, 1961, p. vi. See also Robert A. Bicks, "The Federal Government's Program on Identical Bids," Antitrust Bulletin, Vol. V, November, 1960, pp. 617-626.

${ }^{2}$ United States v. Chas. Pfizer Co., Inc., 217 F. Supp. 199 (1963) at 201 . 
In some circumstances, the primary problem is one of detecting the chiselers either by direct means or by inferring the presence of price cutting by observing changes in market shares. ${ }^{1}$ Where supply prices on individual contracts are public information, however, the problem is not one of detection but of insuring that all firms benefit from the presence of an arrangement and all recognize that the arrangement would disintegrate in the presence of cheating.

A likely problem in any cartel arrangement is the asymmetry which exists among member firms and it is this asymmetry which suggests that some may benefit more than others. It becomes quite possible that the rewards from adhering to the agreement for some firms are less than the temporary gains achieved from undercutting the cartel price. At the least, cartel stability is likely to be undermined in circumstances where the gains to some firms from cartels are relatively small. Since asymmetry among member firms generally exists, cartel strategies must be vitally concerned with the problem of the allocation of rewards.

- Our focus here is on markets characterized by open bidding. In such markets, detailed product specifications are established by each buyer so that product differentiation among sellers is relatively small. All products offered for sale must meet these specifications, so that price represents the crucial factor which distinguishes one seller from another. Second, in markets where the buyer is a public agency, there is often a statutory requirement to accept the low bidder. In these cases, the products

${ }^{1}$ An analysis of this problem is presented in George J. Stigler, "A Theory of oligopoly," Journal of Political Economy, February 1964. 
of different sellers must, for this reason also, be considered as homogeneous. Third, there is frequently immediate public disclosure of all bids--to those which fail to gain the contract as well as to the one which succeeds. The requirement of full disclosure has important implications for price behavior for it insures that all rivals will quickly learn of attempts to undercut a specified cartel price. 1 In markets of this sort, a degree of secrecy and uncertainty regarding the actions and motives of rivals is essential for effective price competition, and it is such considerations which are specifically foreclosed by open bidding. Cartel arrangements in these circumstances, therefore, may be quite different from those which exist under other market conditions.

Two primary types of cartel strategies are probable responses to open bidding. The first is an agreement to set identical bids among member firms to insure that no measure of price-shading occurs. The agreed upon price generally represents a high profit margin so that all benefit. Moreover, the open disclosure requirement provides the primary vehicle of enforcement so that all know if the agreement has been violated.

${ }^{1}$ Stigler writes in this regard that "the system of sealed bids publicly opened with full identification of each bidder's price and specifications is the ideal instrument for the detection of price cutting." Stigler, 으. cit., Pp. 44-45. 
Whatever the impact of such a cartel strategy on prices and profit margins, the effect on the number of contracts received by each firm is more difficult to determine. Buyers have little basis by which to choose among rival sellers. Coins may be tossed, or more likely, firms with more personable salesmen chosen. In fact, some public bodies divide orders among competing bidders. ${ }^{1}$ Output levels thus represent the outcome of a random process which depends essentially on the procedures used by buyers to choose among equally positioned sellers.

An alternative strategy is to rotate low bid positions among the various sellers. Specific firms are assigned individual contracts and competing sellers are required in these instances to "bid high." It is essential to the scheme that competing sellers bid sufficiently high so that the specified winner can still receive a generous return. While various mechanisms can be used for bid rotation, a well-documented scheme is the elaborate "phases of the moon" formula developed in the electrical manufacturers conspiracy. 2

There is no obvious reason why profit margins should be different with this cartel strategy than the other. However, it may have quite different implications for the number of contracts obtained and the output levels of individual firms. In this case, market shares are set by cartel agreements and not left to the whims of buyer preferences. While the degree of

${ }^{1}$ See for example the record in United States v. Chas. Pfizer Co., 217 F. Supp. 199 (1963).

${ }^{2}$ Charles A. Bane, The Electrical Equipment Conspiracies, New York, 1973, pp. 5-6. 
uncertainty regarding prospective output levels is reduced so long as the agreement is maintained, this is not the only gain. By providing a mechanism by which output levels can be divided among firms, it essentially provides a vehicle as well for the division of cartel profits.

While this discussion points to the general superiority of a rotating bid strategy over one founded on identical bids, it has been largely impressionistic. We examine these issues further with the help of a more formal model of cartel strategy.

\section{A Model of Cartel Behavior}

In this analysis, we compare the prospective gains to member firms from two alternative strategies. The first is one of identical bids where all members are required to bid equally on available contracts. The second strategy is one of rotating bids in which member firms are allocated specific market shares and a scheme designed to rotate the low bid position. While the latter permits greater control to be maintained over the profits of member firms, it also is likely to involve greater costs of coordination. To examine this problem formally, we consider that there are $T$ identical contracts available for bidding in a given period of time and that al1 member firms bid on all contracts. If a 11 bids are equal, then the number of contracts received by any given firm is a random variable which follows a binomial distribution:

$$
f(R)=\left(\begin{array}{l}
T \\
R
\end{array}\right)\left(\frac{1}{N}\right)^{R}\left(1-\frac{1}{N}\right)^{T-R}
$$

where $R$ is the number of contracts received and $N$ is the number of member firms. Note that what is assumed here is that all firms have an equal chance of receiving a given contract so that this probability is the 
reciprocal of the number of firms. ${ }^{1}$ For large $T$, this distribution can be approximated by the normal distribution, where $E(R)=T / N$, and $\operatorname{var}(R)=$ $T(N-1) / N^{2} \cdot 2$ Since the products of competing sellers are considered identical, all have the same probability of obtaining the contract when a uniform price is set. In these circumstances, the prospective buyer is forced to use some process, here considered random, of choosing among competing sellers.

In contrast to an identical bid arrangement, a rotating bid cartel necessarily maintains control of the distribution of sales. The low bidder on individual contracts is specified so that the number of contracts received is a determined rather than stochastic variable. With identical products, and with the requirement that buyers select the low bidder, the number of contracts obtained for each firm is determined. What is suggested thereby is that an important implication of a rotating bids cartel arrangement is the elimination of the variability which results when identical bids are tendered.

While the prospective market share for individual firms depends on the explicit cartel arrangement, we specify at this point that this agreement takes the form of assigning contracts to each firm to maintain its existing market share over both bidding and non-bidding sales. If $s_{j}$ is the

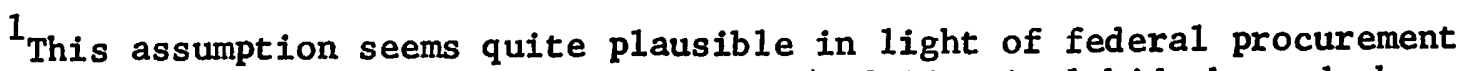
regulations which provide that awards in cases of identical bids be made by lottery, subject to several generally inoperative qualifications. See Joint Economic Committee U.S. Congress, op. cit., P. vii.

2 Actually, since $R$ is constrained to be non-negative, we should use the truncated normal distribution, $\hat{f}(R)=f(R) \cdot I(R) /(1-F(0)$ ) where $F(0)$ denotes the cumulative normal distribution from minus infinity to zero and $I(R)$ equals unity for $R$ in the range from zero to infinity and zero elsewhere. The full normal distribution should be viewed as an approximation to this function. 
pre-existing market share for the jth firm, then the assigned number of contracts for this firm is $s_{j} T$.

Whatever the benefits associated with a rotating bid arrangement, there are also likely to be higher coordination costs. Like other business activities, the establishment and maintenance of cartels are not costless, and coordination costs are likely to be higher with rotating bid schemes. Although there may be cost differences between the two types of agreements, in neither case is cost likely to be dependent on output and hence the optimal price will generally be the same in both cases and lie relatively close to the monopoly price. If $M$ equals the profit margin per contract before cartel costs earned on a contract under either scheme, then unit profit net of such costs can be specified as $M(I B)=M-C(I B)$, where the latter term represents unit coordination costs associated with an identical bid cartel. Similarly, $M(R B)=M-C(R B)$. Since we assume that $C(R B)$ is greater than $C(I B), M(R B)$ is less than $M(I B)$. If $M$ is normalized by setting unit costs, which are assumed equal for all firms to unity, then expected profits from an identical bid arrangement are given by $\mathrm{TM}(\mathrm{IB}) / \mathrm{N}$, and profits with a rotating bid arrangement are $s_{j} \operatorname{TM}(R B)$.

Our problem now is to compare the value to an individual firm of the distribution of profits associated with an identical bid arrangement with the certain profits which result from rotating bids. While many approaches could be used, a convenient one is to assume a utility function over profits in which the degree of absolute risk aversion is held constant. ${ }^{1}$ This

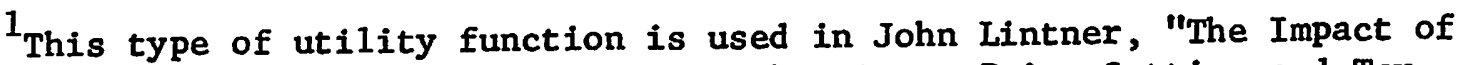
Uncertainty on the 'Traditional' Theory of the Firm: Price-Setting and Tax Shifting," J. W. Markham and G. F. Papanek, eds., Industrial Organization and Economic Development: In Honor of E. S. Mason, 1970, pp. 238-265. Lintner suggests that this utility function is plausible where the actions taken would not have a major impact on the total net wealth of the firm. So long as an important non-bidding market exists, not covered by the cartel arrangement, this formulation of the utility function appears quite reasonable. 
utility function is of the form:

$$
\begin{aligned}
\mathrm{U}(\pi)=\mathrm{a}-\mathrm{be} \mathrm{e}^{-\rho^{*} \pi} \quad-\infty & <\mathrm{a}<\infty \\
0 & <\mathrm{b}<\infty \\
\rho^{*} & =-\frac{\mathrm{d}^{2} \mathrm{U} / \mathrm{d} \pi^{2}}{\mathrm{dU} / \mathrm{d} \pi}
\end{aligned}
$$

So long as profits are distributed normally, as assumed here, maximizing the expectation of this function is identical to maximizing: 1

$$
\begin{array}{ll}
\hat{\pi}=\bar{\pi}-\rho \sigma_{\pi}^{2} & \bar{\pi}=\mathrm{E}(\pi) \\
& \rho=\rho * / 2
\end{array}
$$

This expression is the certainty equivalent of profits earned through an identical bidding cartel which can be compared with the amount of profits earned from a rotating bid arrangement.

In this analysis, it is convenient to treat "large" and "smal1" firms separately. Small firms are those whose market share is less than the average share of member firms, while large firms are those with larger than average market shares. That is:

$$
\begin{array}{ll}
s_{j}=\frac{1}{N}+v_{j} & v_{j}<0 \text { for "sma11" firms } \\
v_{j}>0 \text { for "large" firms }
\end{array}
$$

With this framework, we can now examine the difference between profits earned in a rotating bid cartel and the certainty equivalent of profits earned in an identical bid agreement.

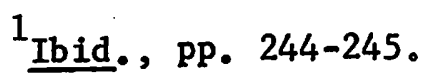


Profit Perspectives Under Alternate Cartel Regimes

Profits will differ under the alternate regimes in several respects. Not only will aggregate profits to the cartel differ in amount but also the distribution of profits among member firms is altered.

For an individual firm, the difference between profits earned with rotating bids and expected profits under an identical bid arrangement can be written:

$$
s_{j} \operatorname{TM}(R B)-\frac{T}{N} M(I B)
$$

Substituting from (4) and using the notation provided above, this expression can be rewritten:

$$
T\left[v_{j} M(R B)-\{C(R B)-C(I B)\} / N\right]
$$

In the discussion below, the function defined by the term in square brackets is indicated by $\Psi$.

If we now concentrate on "large" firms, which are those for whom $v_{j}$ is positive, the sign of this expression turns on the relative absolute values of the two terms. A positive value indicates that the profits of large firms with rotating bids exceed expected profits with an identical bid arrangement, while a negative value suggests the opposite.

An important feature of this expression is that coordination costs under both types of agreements surely increase with the number of firms party to the agreement. At some point, these costs must exceed the profit margin per contract so that the first term becomes negative. Then so long as cartel coordinating costs with rotating bids exceed those with identical bids, the entire expression must be negative for some large value of $N$. Consider how the difference between coordinating costs under the two 
types of regimes is likely to vary with the number of firms. Since the construction of a rotating bid arrangement requires agreement on market share allocations as well as on price levels, while an identical bid scheme covers only the latter, these costs should be higher for the former than the latter for all values of $\mathrm{N}$. If a rotating bid arrangement requires two communication flows between each pair of member firms while an identical bid arrangement requires only one, and if cartel coordinating costs depend entirely on the number of communication flows, ${ }^{1}$ this cost differential should be proportional to the combinatorial expression $[N(N-1)] / 2{ }^{2}$ What is required here is the assumption that it is no more costly to arrive at an arrangement allocating market shares than it is to determine the cartel price, The cost of each information flow can therefore be indicated by the constant $K$, so that aggregate coordination costs are $[\mathrm{KN}(\mathrm{N}-1)] / 2$. If, moreover, the costs of each communication are borme equally by the two parties to it, then differential coordination costs per firm are given by $\alpha(\mathrm{N}-1)$, where $\alpha=\mathrm{k} / 2$.

With these assumptions regarding the structure of cartel costs, the difference between profits earned with rotating bids and expected profits

${ }^{1}$ Coordination costs per contract are viewed here as fixed with respect to the number of contracts but variable with respect to $N$. Changes in the number of contracts thereby do not affect the cost of determining the initial price or market shares.

2 If each pair of firms must communicate, the number of required contacts is $[\mathrm{N}(\mathrm{N}-1)] / 2$ with both regimes. However, in a rotating bid scheme, each contact contains two information flows whereas only one is necessary with identical bids. For related discussion of the relationship between coordination costs and the number of firms, see A. Phillips, Market Structure, Organization and Performance (Cambridge: Harvard University Press, 1962), PP. 29-30 and 0. E. Williamson, "A Dynamic Theory of Interfirm Behavior," Quarterly Journal of Economics (November 1965), p. 600. 
under an identical bid arrangement [expression (6)] is positive so long as $:^{1}$

(7) $\quad \frac{M}{\alpha}>2[N-1]+\left[\frac{N-1}{N}\right] \frac{1}{v_{j}}$

Note that $M$ has been normalized by setting average production costs equal to unity. Unit cartel coordination costs are therefore measured on the same scale, which suggests that $\alpha$ is less than unity and may be quite small. In this case, the value taken by the left-hand side of (7) may be rather large. As indicated, the right-hand side of this expression depends not only on the value of $\mathrm{N}$ but also on $\mathrm{v}_{j}$, which is the difference between the allocated market share and the reciprocal of $N$. As the allocated share falls towards the industry mean, the reciprocal of $v_{j}$ will increase without limit so that the inequality in (7) cannot hold.

Where coordinating costs are relatively low, and the allocated share relatively distant from the industry mean, the inequality in expression (7) should be satisfied at least for low or moderate values of $\mathrm{N}^{2}$ of course, as $\mathrm{N}$ Increases, a point is reached where the inequality is reversed. To obtain more specific results, assumptions or evidence would be needed on the value of $\alpha$ relative to $M$. In the absence of much evidence on this matter, we assume that $\alpha$ is sufficiently low so that expression (7) is satisfied for small values of $\mathrm{N}$.

What has been suggested to this point is that the $\Psi$ function, which represents the difference between profits in a rotating bid scheme and

$1_{\text {Recall that } M(R B)}=M-C(R B)=M-2 \alpha(N-1)$.

2 For a discussion of the necessary deviation of shares from the industry mean, see Appendix III. 
expected profits with identical bidding, will become increasingly negative as $\mathrm{N}$ increases, but is probably positive for small values of $\mathrm{N}$. In addition, it can be demonstrated that $\partial \Psi / \partial \mathrm{N}$ is everywhere negative so that the function declines monotonically with $\mathrm{N}$, and that it approaches a negative asymptote. 1 In short, for a larger firm in an industry with few members, the rotating bid arrangement generates a net increase in expected profits in comparison to an identical bid arrangement, but that benefit is reversed as the number of firms increases.

To this point, we have ignored the influence of the variance in returns associated with identical bid cartels. Using the same notation as before, this variance can be written:

$$
\sigma^{2}(I B)=M(I B)^{2} T\left[\frac{N-1}{N^{2}}\right]
$$

It is then convenient to multiply this variance by $-\rho$, ignore $T$, and indicate the new function by $\theta$. It can then be written:

$$
\theta=-\rho[(M+\alpha)-\alpha N]^{2}\left[N^{-1}-N^{-2}\right]
$$

Since both terms in square brackets as well as $\rho$ are positive, this function is negative for all values of $\mathrm{N}$ except that it reaches a maximum of zero for values of $N$ equal to $[(M / \alpha)+1]$. Note also that $\theta$ does not depend on $v_{j}$ and therefore is independent of the relative position of individual firms. In other words, an identical bidding scheme introduces some profit variance for all firms which is absent in a rotating bid cartel, and this conclusion does not depend on the number of member firms.

${ }^{1} \mathrm{~A}$ demonstration of these results is contained in Appendix $I$. 
The graph of the functions $\Psi$ and $\theta$ for "large" firms can now be drawn as in Figure 1. The indicated relationship between the two functions results from the fact that $N_{3}$ in Figure 1 exceeds $N_{1} \cdot 1$ As indicated, $(\Psi-\theta)$ is positive for values of $N$ less than $N_{2}$. Since $(\Psi-\theta)$ denotes the difference between profits in a rotating bid arrangement and the certainty equivalent of profits with an identical bid scheme, ${ }^{2}$ what is indicated is that rotating bids cartels are preferred even where the $\Psi$ function falls below zero so long as it is smaller in absolute magnitude than the corresponding value of $\theta$. Beyond $\mathrm{N}_{2}, \Psi$ falls below $\theta$ so that identical bidding arrangements are now preferred. Differential coordination costs are greater with an increased number of firms, and the added profit variance is insufficient to overcome this difference. At some further point, moreover, the relationship between $\Psi$ and $\theta$ is again reversed as the effect of the additional profit variance becomes dominant.

The corresponding analysis for "small" firms is somewhat more complex. In an important respect, the analysis is the reversal of that for "large" firms. The $\Psi$ function can be written in the same form as before, although $v_{j}$ is now negative. For small values of $\mathrm{N}$, it can be demonstrated that a sufficient condition for $\Psi$ negative is $:^{3}$

(10) $\quad \frac{M}{\alpha}>2(N-1)$

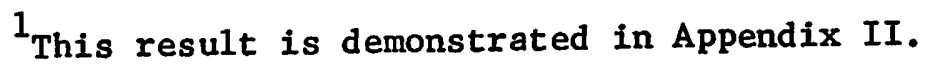

$2_{\text {That is, }(\Psi-\theta)}=\pi(R B)-\hat{\pi}(I B)=\pi(R B)-\left(\bar{\pi}(I B)-\rho \sigma_{\pi}^{2}\right)$.

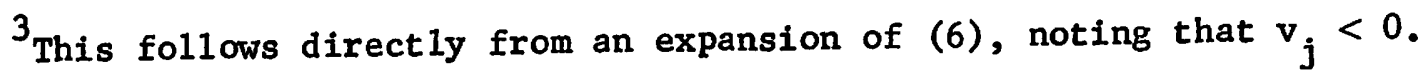


FIGURE 1

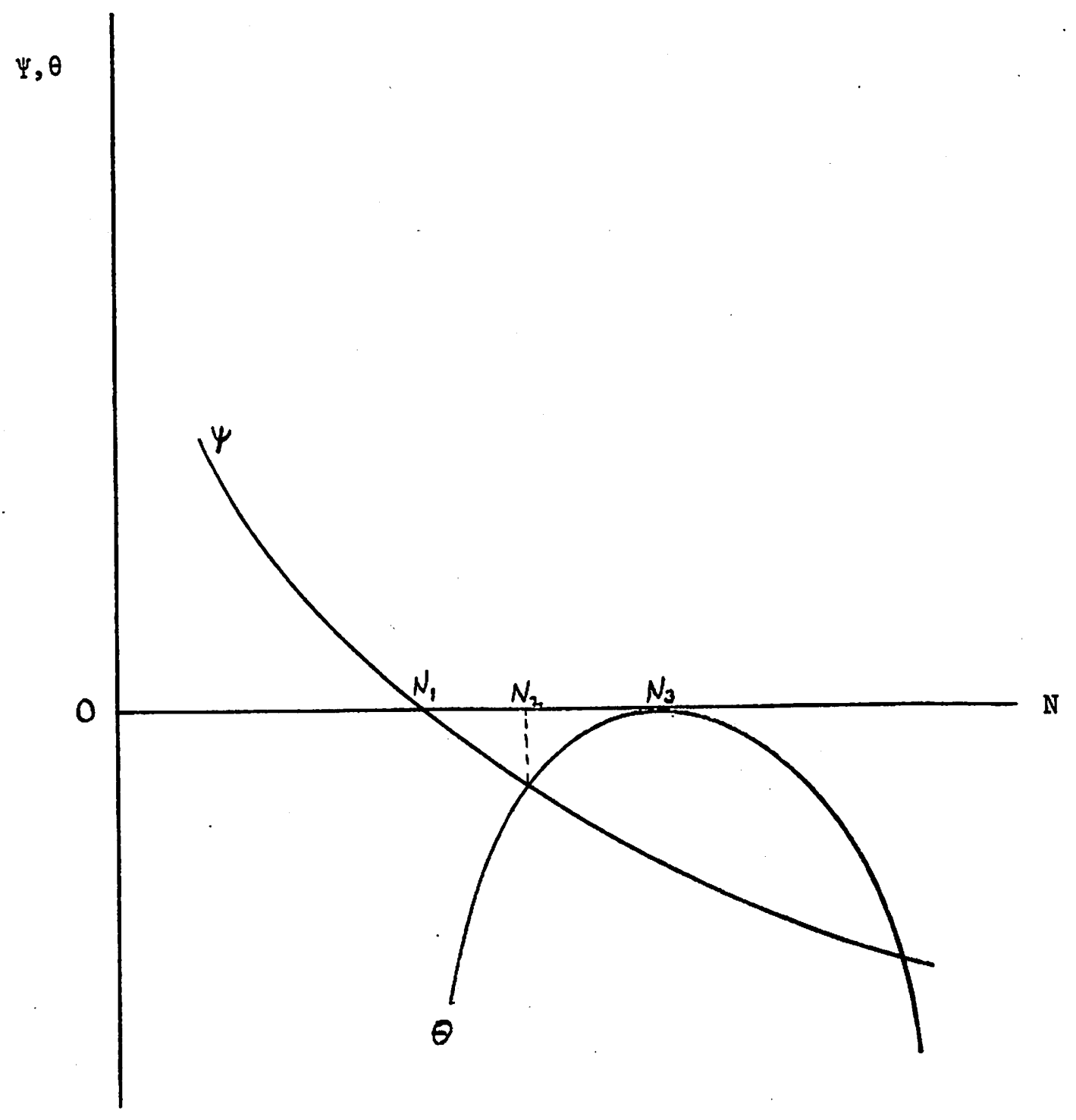


Comparing this expression with (7) above, it is evident that the new condition is less stringent than the previous one, so that if (7) holds, so does (10). Therefore, if the value of the $\Psi$ function for large firms is positive for small $\mathrm{N}$, the corresponding value for sma11 firms must be negative for the same $N$. What is implied thereby is that if a rotating bid scheme promises higher profits for a large firm for some value of $N$, it promises lower profits for a small firm.

In the analysis of large firms, we found that the $\Psi$ function approaches a negative asymptote. In the case of small firms, the asymptote approached may be either positive or negative. As shown in the Appendix, the limit of $\Psi$ as $N$ gets large is $-\alpha\left(2 v_{j} N+1\right)$. A negative asymptote is reached if the term is negative. Since $v_{j}$ is now negative, the former is the case if the absolute value of $\mathrm{v}_{j} \mathrm{~N}$ is less than one-half, while the latter is so if the absolute value exceeds one-half. The position of the asymptote thus depends on the relative size of the firm, with positive asymptotes associated with very small firms and negative asymptotes associated with firms whose market shares fall just below the mean industry level. There are thus two separate cases and it is necessary to consider them separately.

The diagram appropriate for firms whose $\Psi$ functions approach positive asymptotes is drawn in the first part of Figure. 2. The $\Psi$ function is monotonically increasing in $\mathrm{N}$ and convex. Moreover, it can be demonstrated that the $\Psi$ function crosses the abscissa only once. ${ }^{1}$ The $\theta$ function is also given which, it should be recalled, is independent of firm size.

${ }^{1}$ See Appendix IV for these results. 


\section{FIGURE 2}

\section{Case A:}

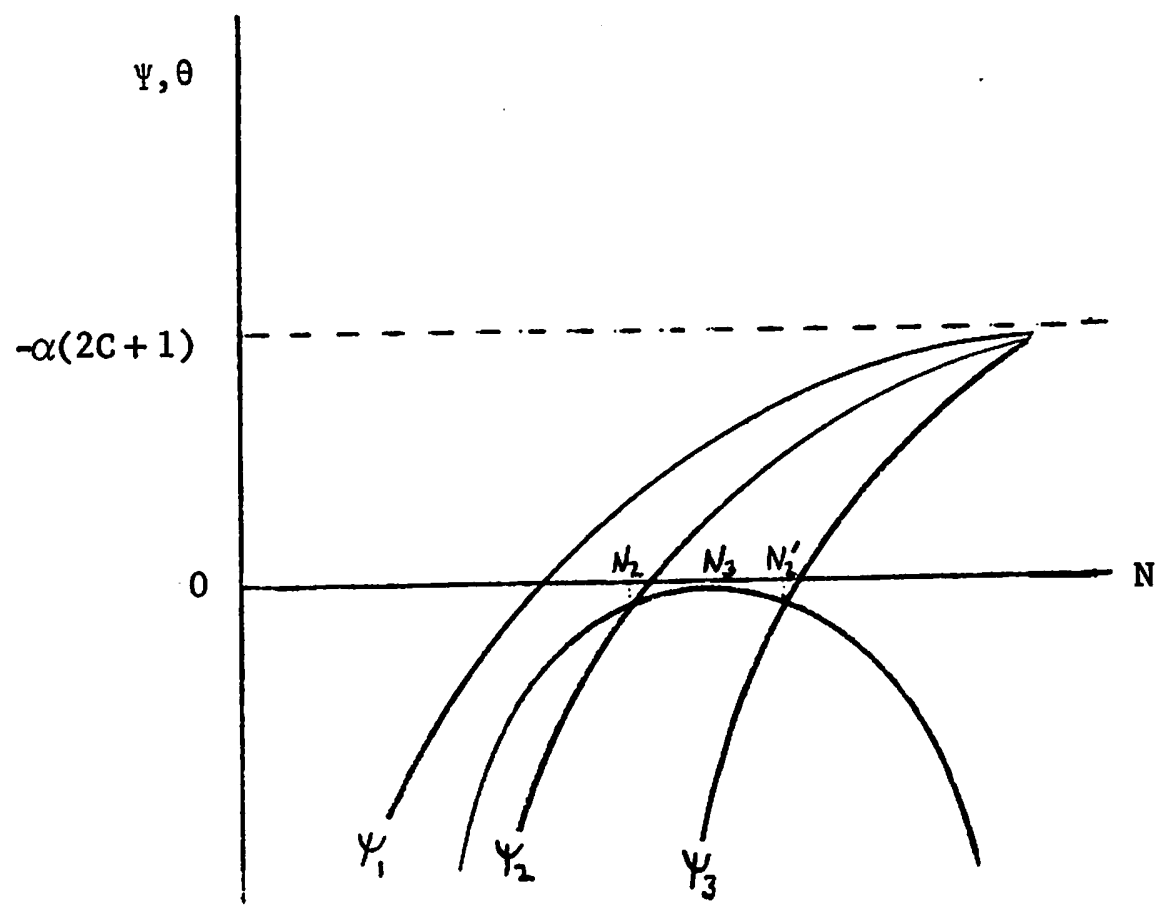

Case B:

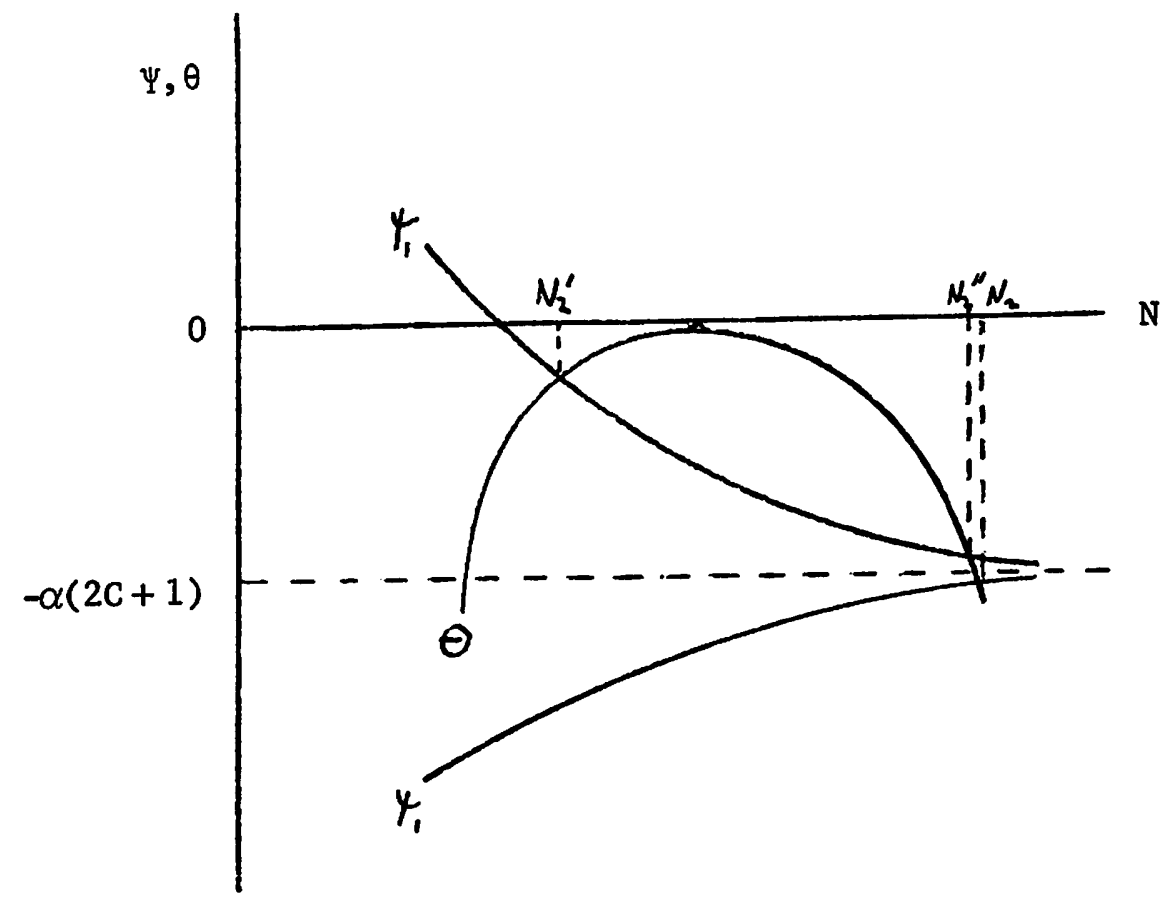


If the relationship between the $\Psi$ and $\theta$ functions is described by $\Psi_{1}$, a rotating bid cartel is preferred to an identical bid cartel even by small firms. In this case, the riskiness associated with an identical bid arrangement outweighs the gains due to a higher market share attained under such an arrangement. This degree of risk aversion seems unlikely, however, and a more reasonable configuration is that given by $\Psi_{2}$ or $\Psi_{3}$. In those circumstances, small firms prefer an identical bid arrangement for values of $\mathrm{N}$ less than $\mathrm{N}_{2}$ and $\mathrm{N}_{2}^{\prime}$ respectively. Average expected gains from increased market shares are dominant. At higher values of $\mathrm{N}$, however, the situation is reversed.

The case of negative asymptotes for small firms is the more important one for it concerns the relatively larger firms in this category. Here, there are two alternate functional forms. The first, denoted $\Psi_{1}$, is a monotonically increasing, convex function which approaches the asymptote from below. In this case, identical bids are preferred for $\mathrm{N}<\mathrm{N}_{2}$ and rotating bids thereafter. The latter observation rests on the fact that the $\Psi$ function approaches an asymptote while the $\theta$ function declines monotonically for $\mathrm{N}$ greater than $\mathrm{N}_{3}$. At some value of $\mathrm{N}$, the greater profit variance associated with identical bid arrangements must dominate. In addition, the possibility of a second intersection for very $\operatorname{small} \mathrm{N}$ cannot be ruled out, so that at low values of $\mathrm{N}$, rotating bid arrangements could be preferred even by small firms in this case.

The second sub-case, denoted $\Psi_{2}$, is a monotonically decreasing, concave function which approaches the asymptote from above and intersects the abscissa only once. ${ }^{1}$ Identical bids are preferred for some intermediate

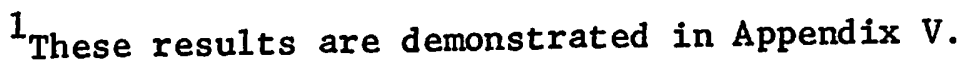


range of $\mathrm{N}$ between $\mathrm{N}_{2}^{\prime}$ and $\mathrm{N}_{2}^{\prime \prime}$. For $\mathrm{N}<\mathrm{N}_{2}^{\prime}$ and $\mathrm{N}>\mathrm{N}_{2}^{\prime \prime}$, a rotating bid scheme is preferred by small firms, which again is associated with the greater profit variance of identical bid cartels in these cases.

\section{Implications for Cartel Strategies}

In the discussion above, we have limited our attention to identical bid schemes which generate equal expected shares. There is a whole class of unequal shares--identical bid arrangements which one can imagine. For example, firms may be restricted to bid on a subset of all contracts in such a way as to generate different expected shares for different firms. It should be clear, however, that all such schemes will be inferior to some rotating bid arrangement, provided that the coordination costs are at least as large as for a rotating bid scheme. The reason is that a rotating bid arrangement could be based on the expected shares which the other scheme would generate, but it would eliminate the share variability which inheres in any identical bid arrangement. Therefore, a rotating bid cartel would be preferred.

The conclusions obtained from the analysis presented above are that for small or moderate values of $\mathrm{N}$, firms with market shares which exceed $1 / \mathrm{N}$ prefer rotating bid arrangements while their smaller rivals probably though not necessarily would prefer an identical bid arrangement. The reasons for this possible difference in preferences are evident. With identical bids, large firms will tend to lose market shares to small firms as the expected shares of all approach the industry mean. The case in which small firms also prefer rotating bids exists only if their risk aversion is sufficiently strong and/or profit variability sufficiently large to outweigh the gain in expected profits which accompanies an identical bid arrangement. 
The problem remains, therefore, as to what outcome is expected.

One approach to a solution, assuming that preferences do in fact diverge, rests on the presumption that at least for a period of time, a cartel can be maintained with the adherence only of the larger firms, while any sort of agreement seems unlikely if larger firms are not included. In general, moreover, large firms would not be expected to abide by an agreement which would lead to a major erosion of their market positions. Smaller firms, however, are in somewhat different circumstances. While the increase in market shares associated with identical bid agreements is preferred, little is lost and there may be substantial gains from accepting a rotating bid arrangement. Existing market shares are maintained but are accompanied by higher realized prices and profit margins. Moreover, the alternative might be only slightly increased market shares but at lower price levels. ${ }^{1}$ This approach suffers, however, from its neglect of the principal power held by small firms in the construction of a cartel strategy. That power is derived from a willingness to quit the agreement, which would leave the cartel a much less stable organization. Surely some form of implicit or explicit bargaining must proceed between large and small firms over the disposition of cartel gains, which in this analysis, can be determined only by allocated market shares since it is presumed that side payments are not feasible.

While it is difficult to be precise in these matters, it seems highly likely that a bargain will be reached which represents a compromise between the interests of the two groups of firms. While relatively large firms

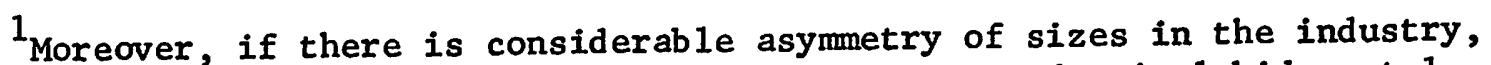
small firms may be especially reluctant to press for an identical bid cartel for fear of retaliation in non-bid markets. 
should be unwilling to accept the share equality implicit in an identical bid arrangement, they may accept some decline in market share in return for cartel stability and the adherence of small firms to the agreement. Small firms, on the other hand, may be willing to accept increased market shares in return for higher effective prices even though full equality is not obtained. With this type of solution, allocated shares are set which maintain some but not all of the pre-existing share differences among firms. This solution is likely to be reached in the interest of cartel stability with the recognition that the most preferred outcome for each set of firms would generally lead to the breakdown of the cartel agreement.

An important implication of any such compromise agreement is that it requires that a rotating bid arrangement be established. Note that an identical bid agreement represents total compliance with the interests of smaller firms and therefore hardly represents a compromise. Only with some form of rotating bid scheme can control be maintained over the shares of cartel profits allocated to individual firms. While the allocated shares may be, different from those assumed in the formal analysis above, the ability to rotate contracts among member firms appears to be a necessary element of a stable agreement. Rotating bid arrangements are therefore the most likely outcome.

Some evidence on this last point is contained in a description of . the electrical manufacturers conspiracy which provides an outstanding recent example of cartel behavior. Allocated market shares for each member of the conspiracy in two product classes are given in Table 1 along with actual market shares for a11 sales in 1950. The evidence on Power Transformers is fully consistent with the analysis above. The two leading firms appear willing to give up market shares in the interests of cartel 
Table 1

ALLOCATED SHARES: ELECTRICAL MANUFACTURERS CONSPIRACY

Company

A1located

Actual Market Share: mid 1950's

(\%)

Share: 1950

(\%)

A. Power Transformers (SIC 36152)

General Electric

30

We stinghouse

Allis-Chalmers

Maloney Electric

10

7

McGraw-Electric

8

5

Wagner Electric

5

4

B. Switchgear and Switchgear Apparatus (SIC 36161)

General Electric

39

Westinghouse

ITE

Allis-Chalmers

Federal Pacific
35

11

8

7
36

35

11

5

N.A.

Notes: The allocated shares of Power Transformers, as reported, sum to 98\%. The allocated shares for Switchgear are for Power Switchgear. Not all suppliers of switchgear were members of this cartel and therefore the total does not add to $100 \%$.

N.A. - Not available.

Sources: John Herling, The Great Price Conspiracy, New York, 1962, and Federal Trade Commission, Value of Shipments Data by Product Class for the 1000 Largest Manufacturing Companies of 1950, Washington, 1972. 
stability while a rotating bid arrangement is maintained. In the case of Switchgear, the evidence is less clear. However, contrary to the assumptions of the model, not all suppliers of this commodity were members of the agreement. Therefore, the fact that the largest relative increase went to the leading firm must be explained by other considerations.

\section{Concluding Comments}

Except in extreme circumstances where the preferences of smaller firms are dominant, identical bidding arrangements are unlikely to be maintained among competing firms. Although the coordination costs of rotating bid agreements are generally higher, the gains associated with the control of market allocations as well as the elimination of an element of market uncertainty, suggest that such arrangements are the dominant form of cartel organization. To the extent that this conclusion is correct, the focus of past government policy on the presence of identical bids in highly concentrated industries is surely misplaced. Indeed, the presence of such bids is such an unlikely cartel strategy that there are reasons for inferring, at least without further evidence to the contrary, that identical bids are more indicative of the absence than the presence of a cartel agreement.' Judicial inferences to the contrary are especially hazardous.

${ }^{1}$ our argument is not that identical bidding in concentrated industries is non-existent, but rather that it will not generally be selected as a cartel strategy. Patterns of identical bidding may simply reflect the recognition of mutual dependence in such industries. For a discussion along those lines, see F. M. Scherer, "Focal Point Pricing and Conscious Parallelism," Antitrust Bulletin, Summer 1967, pp. 495-503. 


\section{APPENDIX}

I. Let $\Psi$ denote the bracketted expression in (6) in the text. Then

$$
\Psi=v_{j} M-2 v_{j} \alpha(N-1)-\alpha(N-1) N^{-1}
$$

To evaluate $\partial \Psi / \partial N$ for a specific firm, we hold the relative market share of that firm constant as $\mathrm{N}$ varies. The relative market share is indicated by $s_{j} / N^{-1}$ or $s_{j} N$. Since $s_{j}=\frac{1}{N}+v_{j}$, we hold $v_{j} N=c$, where $c$ is a constant. Substituting for $v_{j}$ in (A1) and rearranging, we obtain,

$$
\Psi=[M c+\alpha(2 c+1)] N^{-1}-\alpha(2 c+1) \text {. }
$$

Therefore:

$$
\frac{\mathrm{d} \Psi}{\mathrm{dN}}=-[\mathrm{Mc}+\alpha(2 c+1)] \mathrm{N}^{-2}
$$

Since for large firms, $v_{j}>0, c>0$ so that this derivative is negative for all values of $\mathrm{N}$. Note also that as $\mathrm{N}$ becomes infinitely large, $\Psi$ approaches $-\alpha(2 c+1)$, which is negative since $c$ is positive.

II. Refer to Figure 1. Since $\Psi\left(N_{1}\right)=0$ and $\Psi$ declines monotonically with $N$, (A4) $\quad \mathrm{N}_{3} \gtreqless \mathrm{N}_{1}$ as $\Psi\left(\mathrm{N}_{3}\right) \lesseqgtr 0$.

Evaluate $\Psi\left(N_{3}\right)$ and recall that $N_{3}=\frac{M}{\alpha}+1$,

$$
\Psi\left(N_{3}\right)=v_{j} M-2 v_{j} \alpha\left[\frac{M}{\alpha}+1-1\right]-\alpha\left[1-\frac{\alpha}{M+\alpha}\right] \leqq 0 .
$$

This expression can be written

$$
\Psi\left(N_{3}\right)=-\left\{v_{j} M+\alpha\left[1-\frac{\alpha}{M+\alpha}\right]\right\}
$$

Since we are dealing with larger firms, $v_{j}$ and therefore the term in braces is positive, and thus $\Psi\left(N_{3}\right)<0$. 
III. As indicated above, the effect of the deviation of relative share from the industry mean, $v_{j}$, is examined for a given value of $N$ such that $v_{j} N$ is a positive constant for large firms. With this in mind, condition (7) in the text can be written:

$$
c>\left[\frac{\mathrm{M}}{\alpha(\mathrm{N}-1)}-2\right]^{-1}
$$

This condition therefore restricts the closeness of relative shares to the mean share which are considered for small N. Evaluating this condition for plausible values of $M$ and $\alpha$ suggests that this condition is not severe. If, for example, $M=0.4$ and $\alpha=0.01$, so that there is a $40 \%$ mark-up and unit coordination costs are $1 \%$ of production costs, c must exceed 0.16 for $\mathrm{N}$ equals 6 . For this value of $N$, therefore, $v_{j}$ must exceed 0.028 , which indicates that relative shares for larger firms must exceed $18.8 \%$ where the industry mean is $16.7 \%$.

IV. Consider expression (A2) above as applied to small firms. Since the condition for $\Psi$ approaching a positive asymptote is $(2 c+1)<0$, and since $c<0$ for small firms, the coefficient of $\mathrm{N}^{-1}$ in (A2) is negative, while the second term is positive. Descarte's theorem guarantees therefore that there is precisely one positive real root to equation (A2) as applied to small firms. ${ }^{1}$ The same conditions are used to demonstrate that this function is monotonically increasing in $\mathrm{N}$.

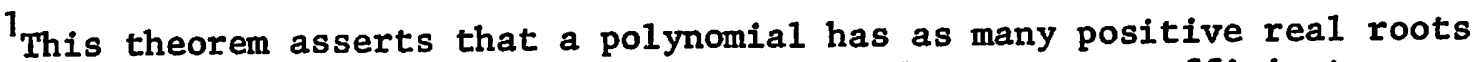
as the number of sign changes in the sequence of non-zero coefficients, or that number minus an even integer. With one sign change in (A2), there can only be one positive real root. 
V. The first and second derivatives of $\Psi(N)$ are:

$$
\begin{aligned}
& \text { (A8) } \frac{\mathrm{d} \Psi}{\mathrm{dN}}=-\left[\mathrm{Mc}+\alpha(2 \mathrm{c}+1) \mathrm{N}^{-2}\right. \\
& \text { (A9) } \frac{\mathrm{d}^{2} \Psi}{\mathrm{dN}^{2}}=2[\mathrm{Mc}+\alpha(2 \mathrm{c}+1)] \mathrm{N}^{-3} .
\end{aligned}
$$

Where $(2 c+1)>0$ and $c<0$, the signs of the two derivatives are ambiguous. Consider two possible cases:

A) $\quad[\mathrm{Mc}+\alpha(2 \mathrm{c}+1)]<0$

In this case, $\Psi$ is monotonically increasing in $\mathrm{N}$. This is shown as $\Psi_{1}$ in Figure 2B. There are no sign changes in the $\Psi$ function and therefore no positive real roots.

B) $[\mathrm{Mc}+\alpha(2 \mathrm{c}+1)]>0$.

In this case, $\Psi$ is monotonically decreasing in N. This is shown as $\Psi_{2}$ in Figure 2B. Here there is one sign change and therefore one positive real root. 